Thermal Testing of Dallas/Maxim iButton Temperature Logger, Model DS1922L, for Flight Qualification on Captive Flight Test Unit-1B (CFTU-1B)

G. Jacobson, A. Lavietes

June 21, 2005 
This document was prepared as an account of work sponsored by an agency of the United States Government. Neither the United States Government nor the University of California nor any of their employees, makes any warranty, express or implied, or assumes any legal liability or responsibility for the accuracy, completeness, or usefulness of any information, apparatus, product, or process disclosed, or represents that its use would not infringe privately owned rights. Reference herein to any specific commercial product, process, or service by trade name, trademark, manufacturer, or otherwise, does not necessarily constitute or imply its endorsement, recommendation, or favoring by the United States Government or the University of California. The views and opinions of authors expressed herein do not necessarily state or reflect those of the United States Government or the University of California, and shall not be used for advertising or product endorsement purposes.

This work was performed under the auspices of the U.S. Department of Energy by University of California, Lawrence Livermore National Laboratory under Contract W-7405-Eng-48. 


\section{Thermal Testing of Dallas/Maxim iButton Temperature Logger, Model DS1922L, for Flight Qualification on Captive Flight Test Unit-1B (CFTU-1B) \\ Test Number 001}

Test performed 26-27 April 2005

Prepared by:

Gerard F. Jacobson

5 May 2005

Engineering Technical Associate

Defense Sciences Engineering Division Lawrence Livermore National Laboratory

Approved by:

Anthony D. Lavietes Engineer

Defense Sciences Engineering Division Lawrence Livermore National Laboratory 


\section{Introduction}

This report documents the flight qualification testing of the Dallas/Maxim iButton temperature logger, model DS1922L, for internal mounting to the W80 Air Launched Cruise Missile (ALCM). A single thermal test was performed utilizing a Thermotron Model S-1.2V, S/N 20330-S, Environmental Chamber, an Agilent 34970A Data Acquisition/Switch unit, S/N MY44002670, with a Agilent 34901A 20 channel multiplexer, S/N MY41038424, and a single J type thermocouple. Start, stop, chamber temperature and temperature profile control of the Themotron was accomplished using a custom LabView VI. Additional chamber thermal data from the Agilent unit, for comparison with the Thermtron thermocouple, was captured using Agilent BenchLink software. The thermal test was performed in Building 131, Room 2273, at Lawrence Livermore National Laboratory, Livermore, California. One hundred twenty eight (128) DS1922L temperature loggers were setup and tested simultaneously.

The test consisted of the thermal profile shown in table 1.1 and Figure 1.1

Table 1.1

Thermal Test Profile

\begin{tabular}{|c|c|c|}
\hline Function & Time, Hours & Temperature, ${ }^{\circ} \mathrm{C}$ \\
\hline Hold & 2 & 25 \\
\hline Ramp & 1 & 80 \\
\hline Hold & 2 & 80 \\
\hline Ramp & 1 & 25 \\
\hline Hold & 2 & 25 \\
\hline Ramp & 1 & -65 \\
\hline Hold & 2 & -65 \\
\hline Ramp & 1 & 25 \\
\hline Hold & 2 & 25 \\
\hline Ramp & Machine limited & 80 \\
\hline Hold & 2 & 80 \\
\hline Ramp & Machine limited & 25 \\
\hline Hold & 2 & 25 \\
\hline Ramp & Machine limited & -65 \\
\hline Hold & 2 & -65 \\
\hline Ramp & Machine limited & 25 \\
\hline Hold & 2 & 25 \\
\hline
\end{tabular}




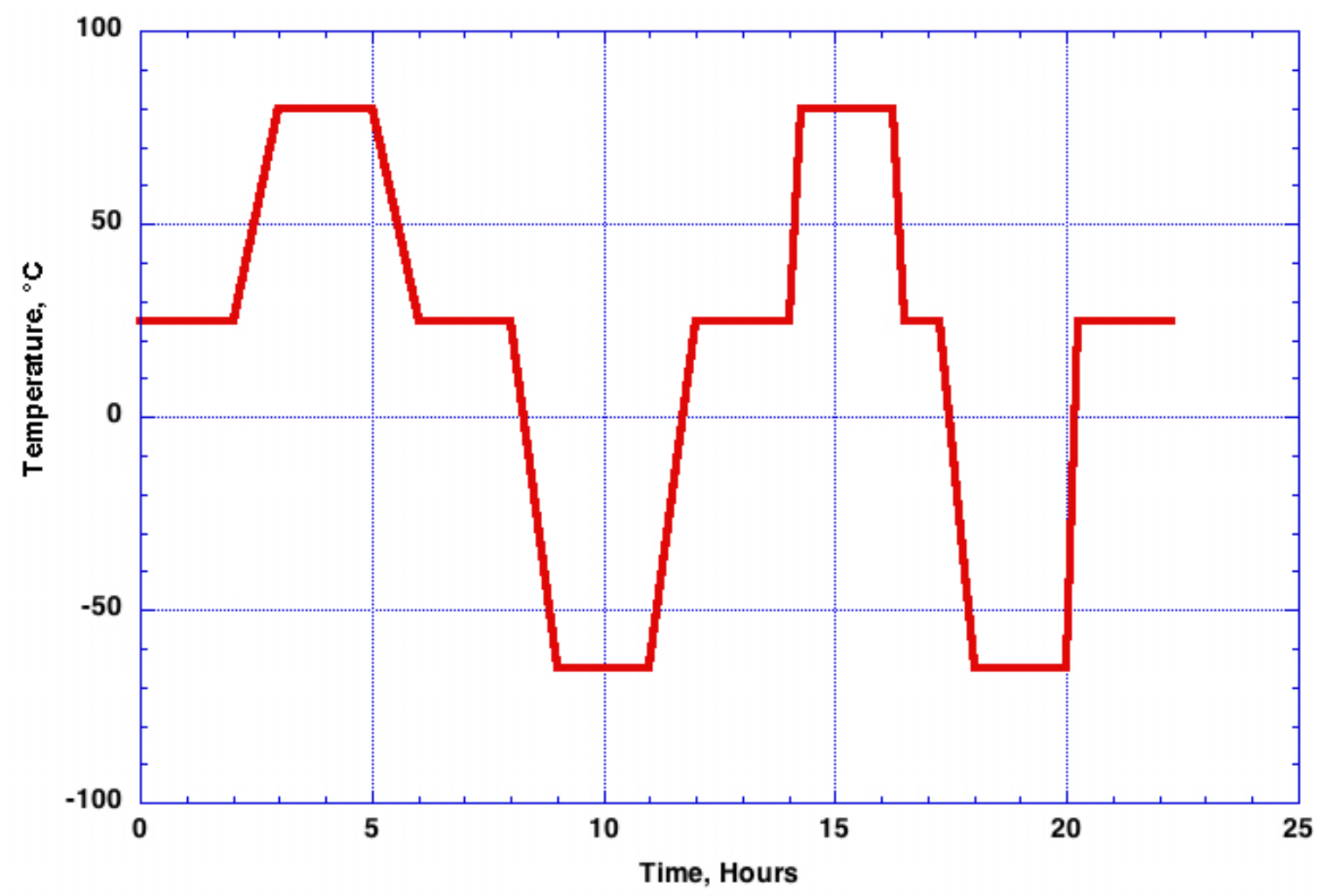

Figure 1.1 - Graph of Thermal Test Profile

\section{Test Setup and Procedure}

One hundred twenty eight (128) DS1922L temperature data loggers were assembled using orange halo tags, Dallas/Maxim model DS9106L-OG, and halo lock rings, Dallas/Maxim model DS9093RA. The halo tags were labeled using a black, finepoint, Sharpie permanent marker with their serial number for easy reading, figure 2.1.

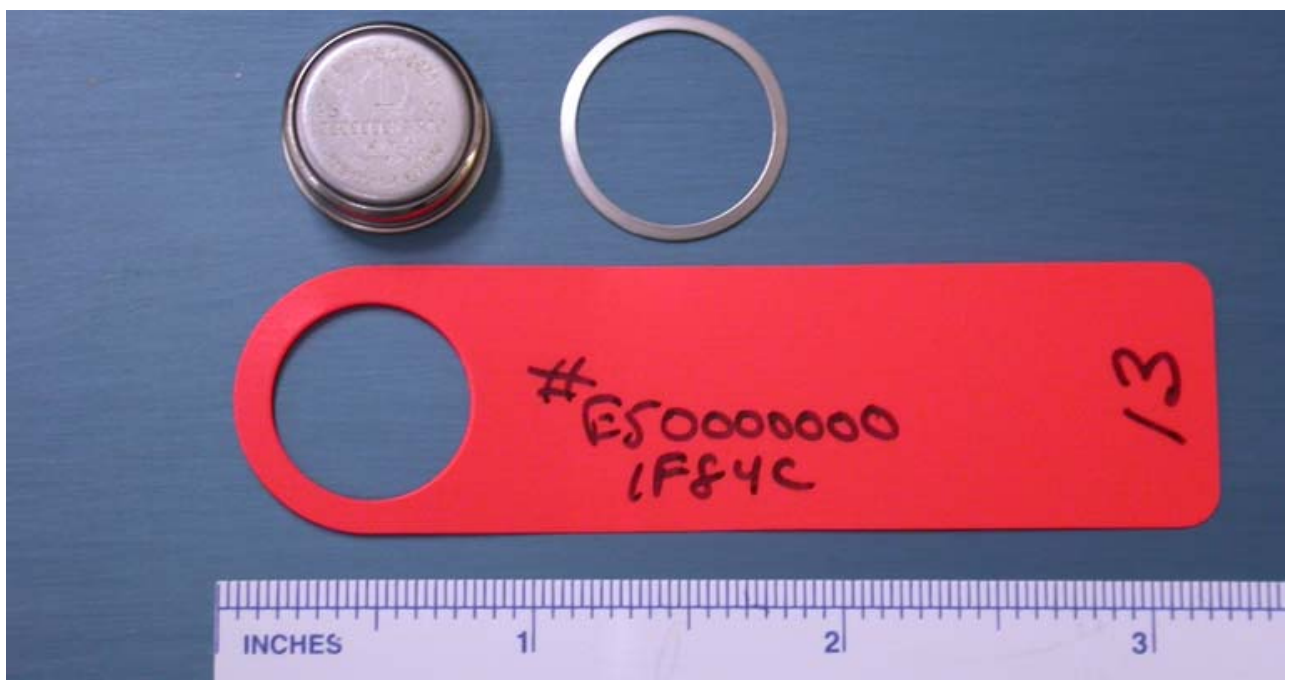

Figure 2.1 - DS1922L, halo tag and lock ring 
The DS1922Ls were configured using ThermoTrack software from Proges-Plus. Due to the large number of DS1922Ls being programmed, 16 mission profiles were created in ThermoTrack. The difference in the profiles was the start delay, which varied from 29 minutes to 59 minutes in 2-minute increments. This was necessary since one can only program 7 DS1922Ls in 1 minute, and we were wanted the one hundred twenty eight (128) DS1922Ls to start within one minute of each other.

Therefore, the parameters of the mission were a start delay from 59 minutes to 29 minutes, $0.5^{\circ} \mathrm{C}$ resolution, and a 160 - second sampling rate. The 160 -second sampling rate allows the DS1922L to acquire 8129, 8-bit readings for 15 days 4 Hours 5 minutes. The 23.5-hour test requires a minimum of 529 samples, which is easily accommodated by the DS1922L.

The one hundred twenty eight (128) DS1922Ls were loaded into the environmental chamber upon a perforated aluminum sheet. A J-type thermocouple, connected to the Agilent 34970A, was inserted into the chamber through the chamber feed-through port on the left side of the chamber, Figures 2.2 and 2.3.

Five minutes before the DS1922Ls were programmed to start, the Agilent 34970A was started, and began capturing data at 10-second intervals. A status check of five (5) DS1922Ls picked at random was performed $\sim 8$ minutes after the scheduled start time to verify they were acquiring data.

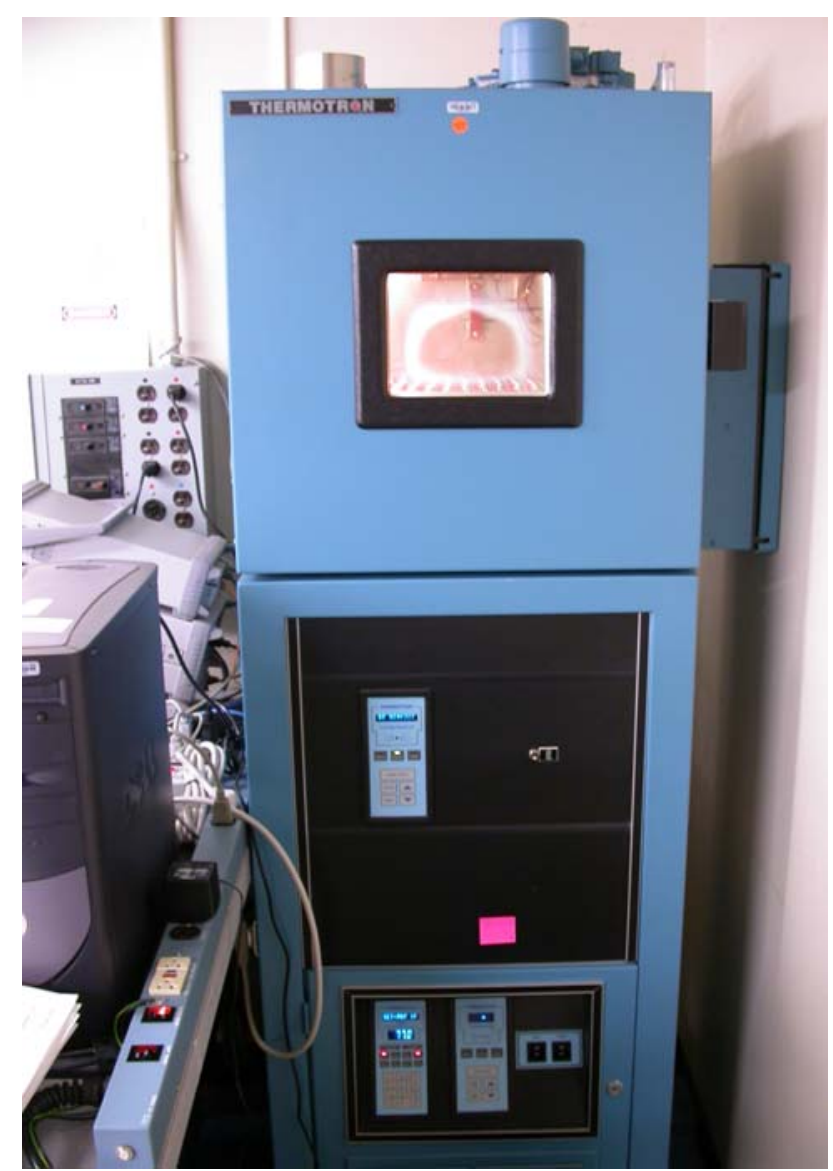

Figure 2.2 - Thermotron Environmental Chamber 


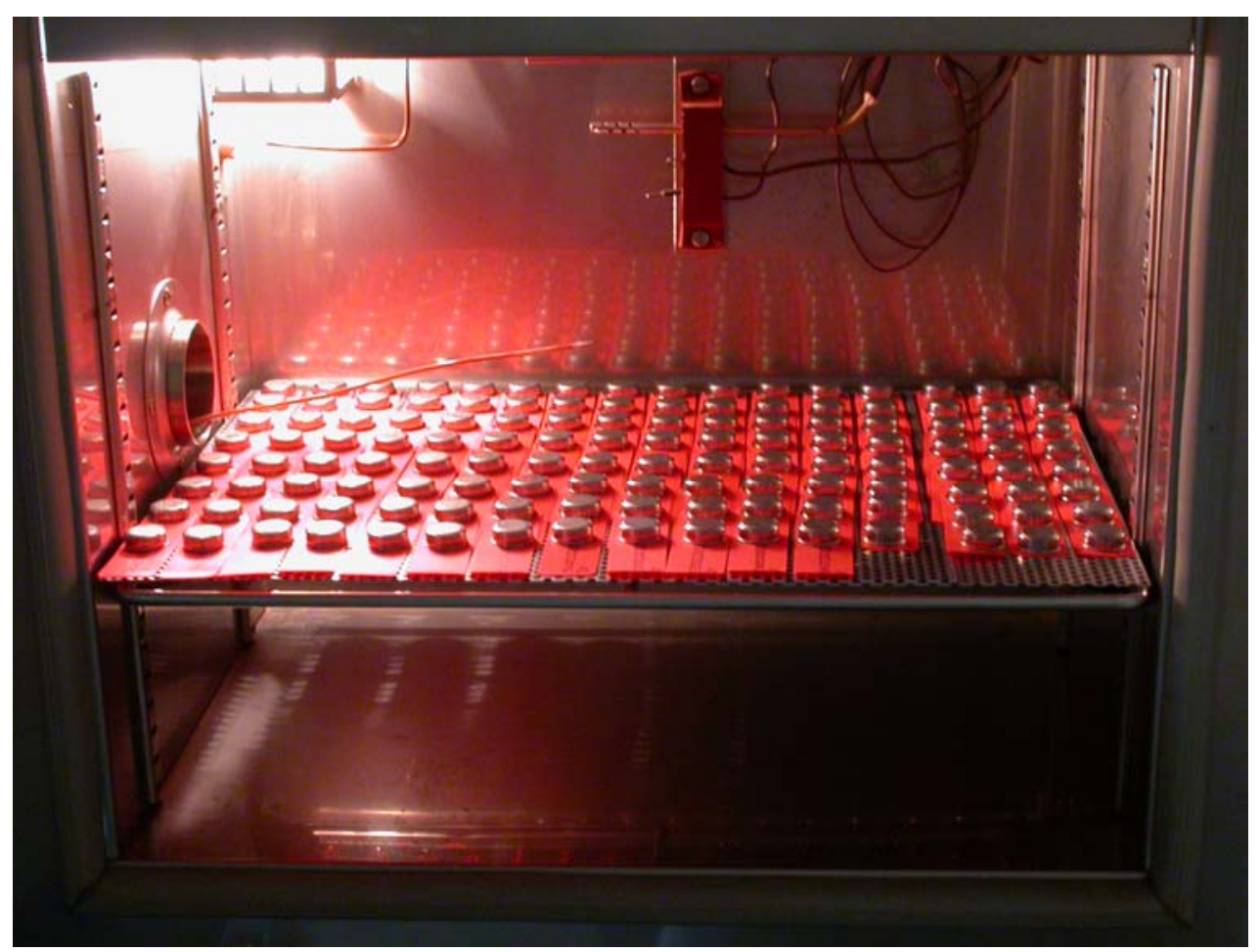

Figure 2.3 - DS1922Ls Loaded in Chamber with J-type Thermocouple Inserted

The LabView program controlling the Thermotron was started at 9:12:32 AM on 4/26/2005 and ran the programmed temperature profile until 7:12:31 AM on 4/27/2005. After the temperature profile was run, the Thermotron shut off and the chamber temperature was left to drift.

While the VI was running, temperature data was captured from the Thermotron at 10 -second intervals. Thermal data continued to be captured by both the Agilent 34970A and the LabView VI until they were stopped at 8:25:25 AM and 8:31:32 AM, respectively. The temperature profiles were saved as .txt files.

At the end of the test period, a status check of the DS1922Ls was performed to verify functionality and data acquisition was then stopped. The data was then downloaded to a laptop, archived and exported to an Excel format file.

\section{Test Results}

Figure 3.1 shows the temperature profile of the Thermotron Environmental Chamber captured by the LabView VI. Figure 3.2 shows the chamber temperature as recorded by the Agilent 34970A J-type thermocouple. As can be seen when comparing the two figures, the temperature in figure 3.1 is a smoothed, averaged signal whereas; the temperature in figure 3.2 is a true representation of the chamber temperature. Figure 3.3 shows a representative temperature profile recorded by the DS1922Ls. The temperature plot in figure 3.2 is similar to the temperature plot in figure 3.3. Figure 3.2 has better resolution due to the 10 -second sampling rate versus the 160 -second sample rate of figure 3.3. 


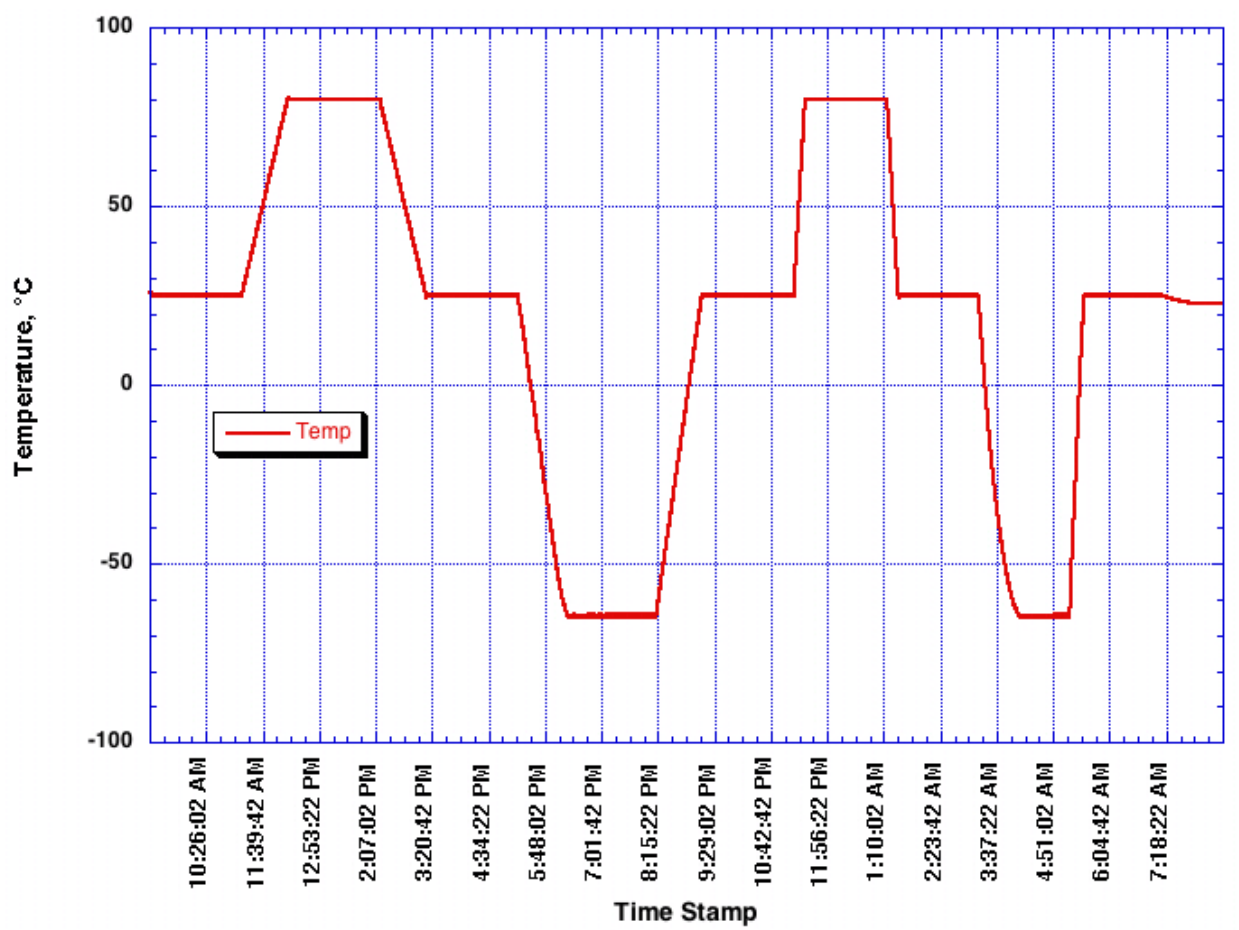

Figure 3.1 - Thermotron Temperature Recorded by LabView VI

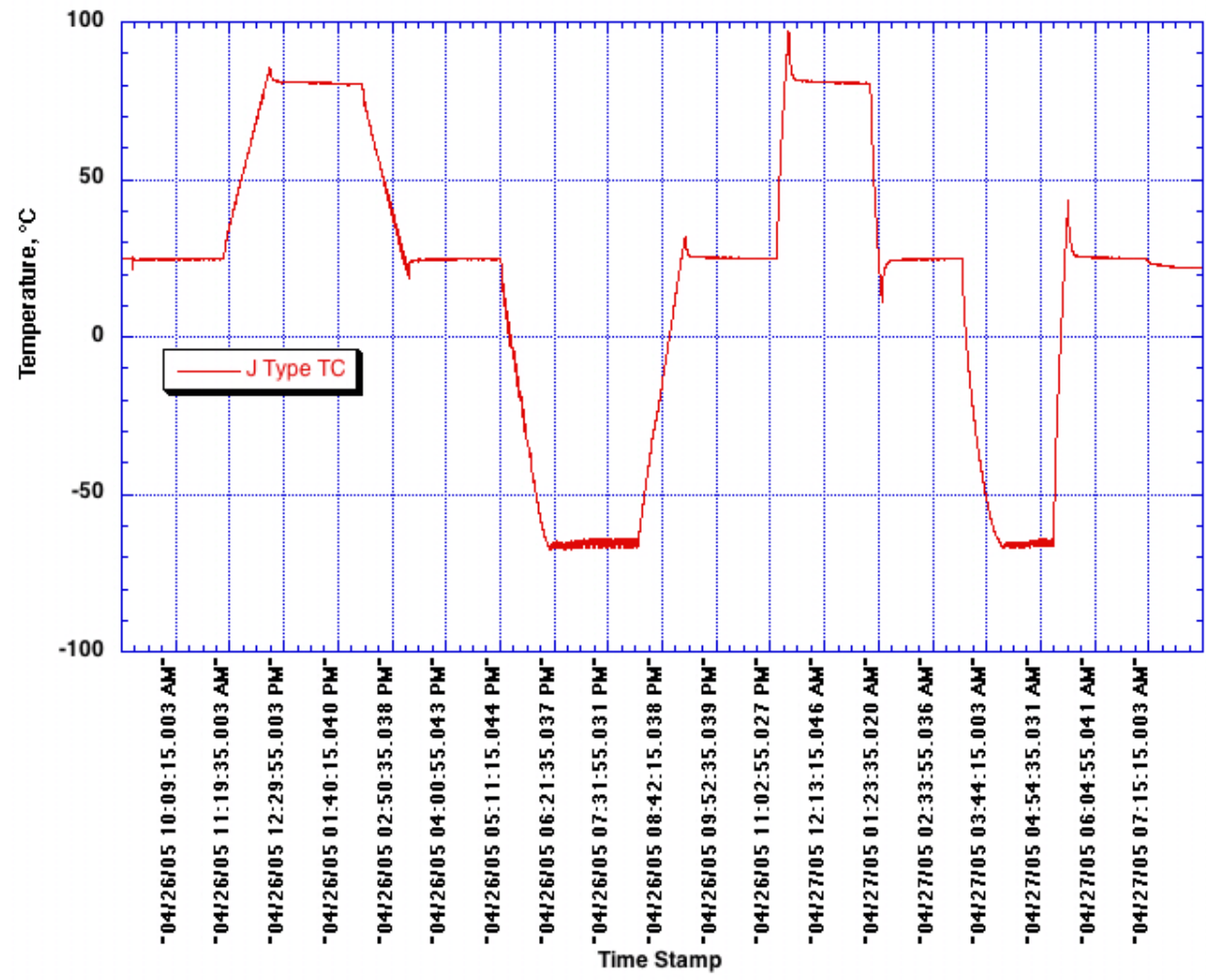

Figure 3.2 - Chamber Temperature Recorded by Agilent 34970A 
DS1922L, S/ N 0000000001F6AE41



Figure 3.3 - Chamber Temperature Recorded by DS1922L Temperature Logger

Of the 128 DS1922L temperature loggers tested, only one failed to mission properly, S/N 4600000001F4FB41. This was from a batch of 20 spare devices whose overlaid temperature profiles are shown in figure 3.4. The failed device is the ramp plot.

\section{DS1922L Temperature Profile, Spares}

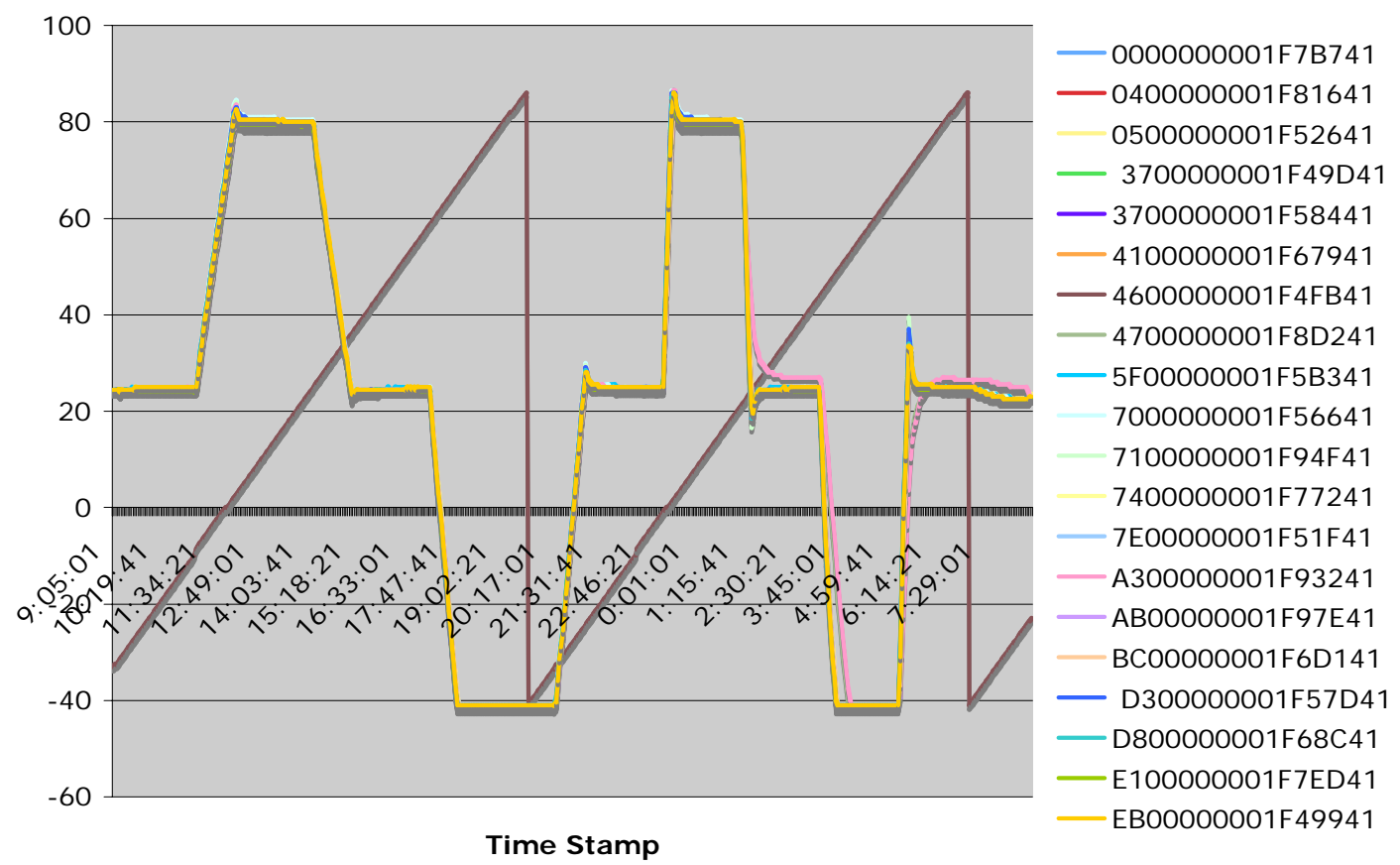

Figure 3.4 -Temperature Profile for 20 Spare DS1922Ls 
The temperature accuracy of the DS1922L, Figure 3.5, is from the Dallas Semiconductor/Maxim DS1922L data sheet. Temperature accuracy is essentially the same for 8-bit data. The difference is in the resolution, $0.0625^{\circ} \mathrm{C}$ for 11 -bit versus $0.5^{\circ} \mathrm{C}$ for 8-bit.

DS1922L TEMPERATURE ACCURACY

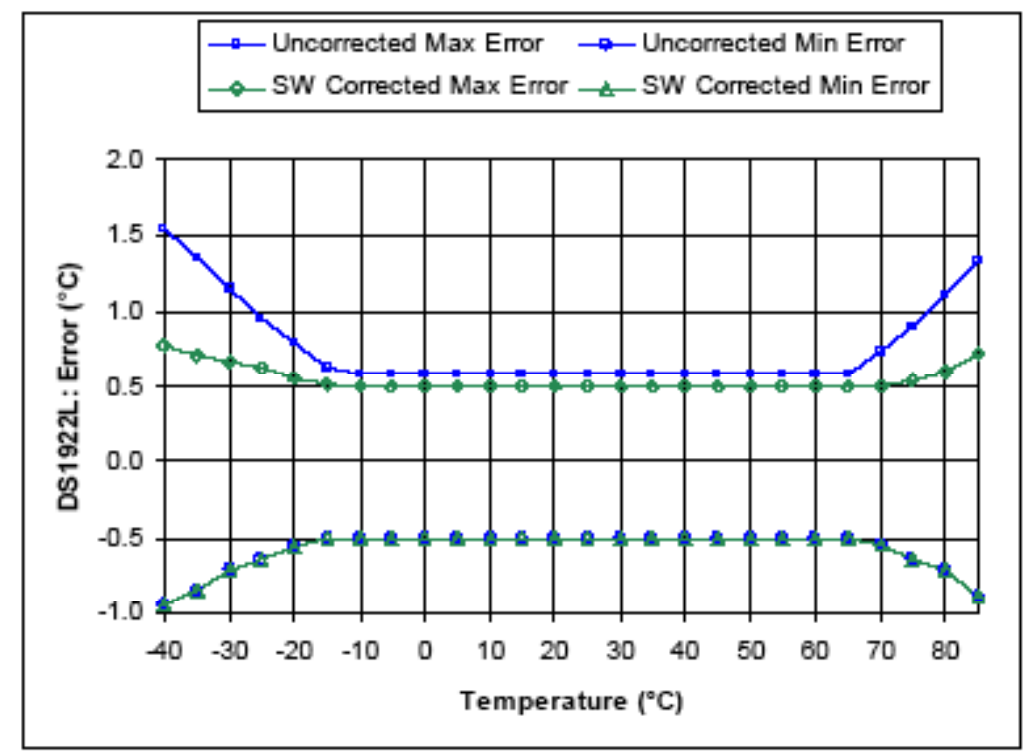

NOTE: The graphs are based on 11-bit data.

Figure 3.5 - DS1922L Temperature Accuracy

Typical temperature accuracy of the tested DS1922Ls, Figure 3.6, fall within the range of accuracy shown in Figure 3.5

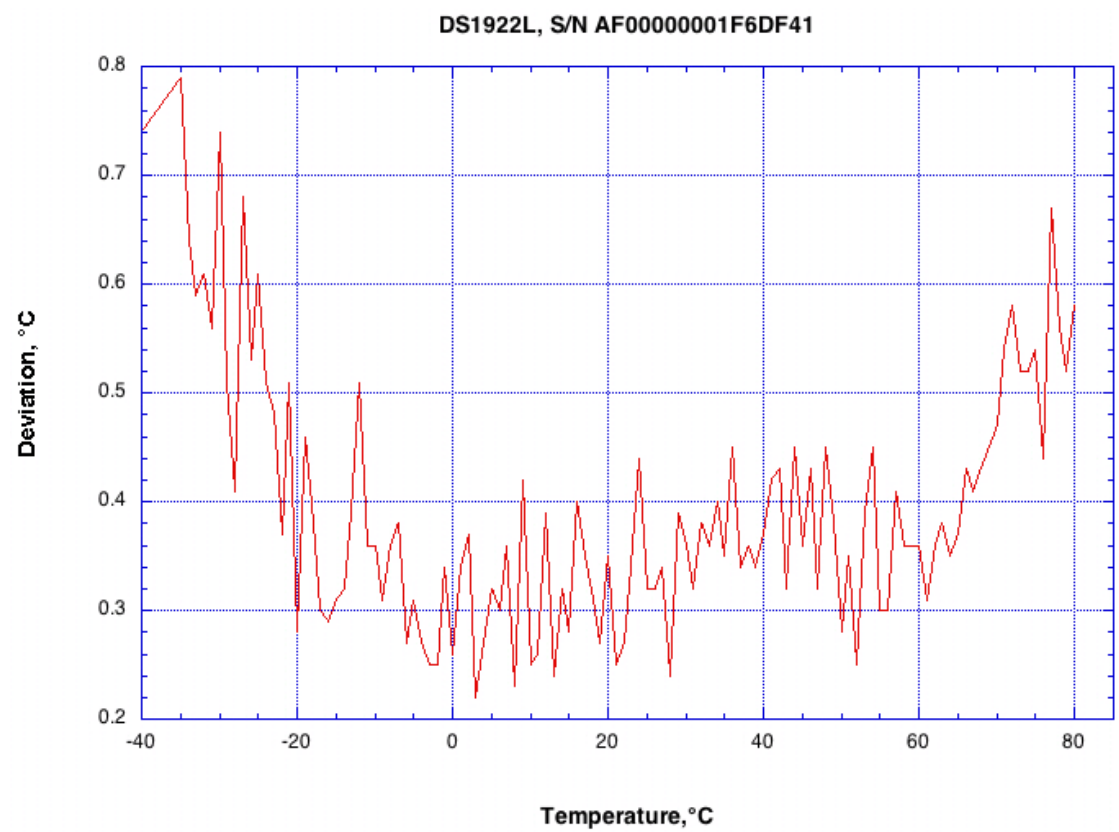




\section{Serial Numbers for Tested Dallas/Maxim iButton Temperature Logger, Model DS1922L}

\begin{tabular}{|c|c|c|}
\hline Sensor ID \# & Pass & Fail \\
\hline D800000001F68C41 & $\mathrm{X}$ & \\
\hline D300000001F57D41 & $\mathrm{X}$ & \\
\hline 7E00000001F51F41 & $\mathrm{X}$ & \\
\hline EB00000001F49941 & $\mathrm{X}$ & \\
\hline 4700000001F8D241 & $\mathrm{X}$ & \\
\hline BC00000001F6D141 & $\mathrm{X}$ & \\
\hline $7400000001 \mathrm{~F} 77241$ & $\mathrm{X}$ & \\
\hline $3700000001 F 58441$ & $\mathrm{X}$ & \\
\hline A300000001F93241 & $\mathrm{X}$ & \\
\hline $0500000001 F 52641$ & $\mathrm{X}$ & \\
\hline 0000000001F7B741 & $\mathrm{X}$ & \\
\hline AB00000001F97E41 & $\mathrm{X}$ & \\
\hline $0400000001 \mathrm{~F} 81641$ & $\mathrm{X}$ & \\
\hline 5F00000001F5B341 & $\mathrm{X}$ & \\
\hline 7100000001F94F41 & $\mathrm{X}$ & \\
\hline 3700000001F49D41 & $\mathrm{X}$ & \\
\hline 7000000001F56641 & $\mathrm{X}$ & \\
\hline 4100000001F67941 & $\mathrm{X}$ & \\
\hline $9300000001 F 26041$ & $\mathrm{X}$ & \\
\hline D900000001F26D41 & $\mathrm{X}$ & \\
\hline 2200000001F4A641 & $\mathrm{X}$ & \\
\hline EF00000001F4BF41 & $\mathrm{X}$ & \\
\hline D600000001F4C741 & $\mathrm{X}$ & \\
\hline 3F00000001F4D141 & $\mathrm{X}$ & \\
\hline 2C00000001F4DF41 & $\mathrm{X}$ & \\
\hline 2A00000001F4EA41 & $\mathrm{X}$ & \\
\hline 4600000001F4FB41 & & $\mathrm{X}$ \\
\hline AD00000001F4FE41 & $\mathrm{X}$ & \\
\hline 9A00000001F4FF41 & $\mathrm{X}$ & \\
\hline 2700000001F51C41 & $\mathrm{X}$ & \\
\hline 3200000001F52741 & $\mathrm{X}$ & \\
\hline B500000001F53341 & $\mathrm{X}$ & \\
\hline 2300000001F53A41 & $\mathrm{X}$ & \\
\hline D500000001F54841 & $\mathrm{X}$ & \\
\hline 4100000001F55241 & $\mathrm{X}$ & \\
\hline F300000001F55441 & $\mathrm{X}$ & \\
\hline D700000001F55B41 & $\mathrm{X}$ & \\
\hline
\end{tabular}




\begin{tabular}{|c|c|c|}
\hline Sensor ID \# & Pass & Fail \\
\hline 8800000001F56D41 & $\mathrm{X}$ & \\
\hline C000000001F57541 & $\mathrm{X}$ & \\
\hline 5600000001F57A41 & $\mathrm{X}$ & \\
\hline BD00000001F57F41 & $\mathrm{X}$ & \\
\hline 4A00000001F58841 & $\mathrm{X}$ & \\
\hline 2400000001F58A41 & $\mathrm{X}$ & \\
\hline 1300000001F58B41 & $\mathrm{X}$ & \\
\hline B000000001F59041 & $\mathrm{X}$ & \\
\hline 0200000001F59641 & $\mathrm{X}$ & \\
\hline $3500000001 F 59741$ & $\mathrm{X}$ & \\
\hline CD00000001F59C41 & $\mathrm{X}$ & \\
\hline FA00000001F59D41 & $\mathrm{X}$ & \\
\hline 9200000001F5AA41 & $\mathrm{X}$ & \\
\hline $9000000001 F 5 B 941$ & $\mathrm{X}$ & \\
\hline 2200000001F5BF41 & $\mathrm{X}$ & \\
\hline 8A00000001F65541 & $\mathrm{X}$ & \\
\hline 9900000001F65B41 & $\mathrm{X}$ & \\
\hline 3E00000001F66641 & $\mathrm{X}$ & \\
\hline D700000001F67041 & $\mathrm{X}$ & \\
\hline $6500000001 \mathrm{~F} 67641$ & $\mathrm{X}$ & \\
\hline AA00000001F67C41 & $\mathrm{X}$ & \\
\hline CB00000001F68241 & $\mathrm{X}$ & \\
\hline $8100000001 \mathrm{~F} 68 \mathrm{~F} 41$ & $\mathrm{X}$ & \\
\hline A700000001F69341 & $\mathrm{X}$ & \\
\hline $2200000001 \mathrm{~F} 69441$ & $\mathrm{X}$ & \\
\hline 0000000001F6AE41 & $\mathrm{X}$ & \\
\hline 7100000001F6C641 & $\mathrm{X}$ & \\
\hline C300000001F6CE41 & $\mathrm{X}$ & \\
\hline AF00000001F6DF41 & $\mathrm{X}$ & \\
\hline 1B00000001F6EC41 & $\mathrm{X}$ & \\
\hline D600000001F6F541 & $\mathrm{X}$ & \\
\hline FF00000001F70C41 & $\mathrm{X}$ & \\
\hline 1600000001F71A41 & $\mathrm{X}$ & \\
\hline A200000001F72941 & $\mathrm{X}$ & \\
\hline CC00000001F72B41 & $\mathrm{X}$ & \\
\hline 9700000001F73B41 & $\mathrm{X}$ & \\
\hline $6100000001 F 74941$ & $\mathrm{X}$ & \\
\hline 0F00000001F74B41 & $\mathrm{X}$ & \\
\hline 9B00000001F75141 & $\mathrm{X}$ & \\
\hline 5200000001F76E41 & $\mathrm{X}$ & \\
\hline
\end{tabular}




\begin{tabular}{|c|c|c|}
\hline Sensor ID \# & Pass & Fail \\
\hline 2600000001F7AB41 & $\mathrm{X}$ & \\
\hline 2400000001F7B841 & $\mathrm{X}$ & \\
\hline 9600000001F7BE41 & $\mathrm{X}$ & \\
\hline 2A00000001F7C141 & $\mathrm{X}$ & \\
\hline F600000001F7C541 & $\mathrm{X}$ & \\
\hline 5700000001F7CD41 & $\mathrm{X}$ & \\
\hline F400000001F7D641 & $\mathrm{X}$ & \\
\hline AB00000001F7E041 & $\mathrm{X}$ & \\
\hline 9E00000001F7F241 & $\mathrm{X}$ & \\
\hline EF00000001F81341 & $\mathrm{X}$ & \\
\hline CB00000001F81C41 & $\mathrm{X}$ & \\
\hline 5900000001F83341 & $\mathrm{X}$ & \\
\hline 9600000001F83941 & $\mathrm{X}$ & \\
\hline 2400000001F83F41 & $\mathrm{X}$ & \\
\hline E500000001F84C41 & $\mathrm{X}$ & \\
\hline $7100000001 \mathrm{~F} 85641$ & $\mathrm{X}$ & \\
\hline 8D00000001F87B41 & $\mathrm{X}$ & \\
\hline 6600000001F87E41 & $\mathrm{X}$ & \\
\hline A400000001F89B41 & $\mathrm{X}$ & \\
\hline 1600000001F89D41 & $\mathrm{X}$ & \\
\hline FB00000001F8AD41 & $\mathrm{X}$ & \\
\hline 0100000001F8B541 & $\mathrm{X}$ & \\
\hline A000000001F8BD41 & $\mathrm{X}$ & \\
\hline E600000001F8DA41 & $\mathrm{X}$ & \\
\hline 7600000001F8E641 & $\mathrm{X}$ & \\
\hline 7400000001F8F541 & $\mathrm{X}$ & \\
\hline 5000000001F8FA41 & $\mathrm{X}$ & \\
\hline 1500000001F91241 & $\mathrm{X}$ & \\
\hline FE00000001F91741 & $\mathrm{X}$ & \\
\hline DA00000001F91841 & $\mathrm{X}$ & \\
\hline ED00000001F91941 & $\mathrm{X}$ & \\
\hline A100000001F92141 & $\mathrm{X}$ & \\
\hline CD00000001F93041 & $\mathrm{X}$ & \\
\hline BC00000001F95641 & $\mathrm{X}$ & \\
\hline C100000001F95A41 & $\mathrm{X}$ & \\
\hline A400000001F98241 & $\mathrm{X}$ & \\
\hline 6B00000001F98841 & $\mathrm{X}$ & \\
\hline 3200000001F98B41 & $\mathrm{X}$ & \\
\hline D900000001F98E41 & $\mathrm{X}$ & \\
\hline B000000001FB2541 & $\mathrm{X}$ & \\
\hline
\end{tabular}




\begin{tabular}{|c|c|c|}
\hline Sensor ID \# & Pass & Fail \\
\hline F200000001FB4F41 & X & \\
\hline 2C00000001FB5841 & X & \\
\hline C100000001FB6841 & X & \\
\hline 6300000002004541 & X & \\
\hline 3A00000002004641 & X & \\
\hline FE00000002009641 & X & \\
\hline F20000000202CE41 & X & \\
\hline 390000000202E241 & X & \\
\hline 3C00000002041741 & $X$ & \\
\hline 1800000002041841 & X & \\
\hline E100000001F7ED41 & X & \\
\hline
\end{tabular}


---- END OF DOCUMENT ---- 